\title{
Egusi seed allergy confirmed using the basophil activation test
}

\author{
Erika Harnik ${ }^{1}$, Zainab Jama ${ }^{2}$, Matthew Kwok ${ }^{2}$, Adam Fox ${ }^{3}$, and Alexandra Santos ${ }^{2}$ \\ ${ }^{1}$ Evelina London Children's Hospital \\ ${ }^{2}$ King's College London \\ ${ }^{3}$ King's College of London
}

September 25, 2021

\begin{abstract}
We report for the first time the case of allergy to egusi seeds in an atopic child of Nigerian origin with allergy to other seeds and nuts. This case highlights the need to know and explore less common foods as potential allergens, the importance of modified skin prick testing and the basophil activation test to support the diagnosis of rare food allergies and of awareness about world cuisine and exotic foods as potential allergens.
\end{abstract}

\section{Egusi seed allergy confirmed using the basophil activation test}

To the Editor,

The vast majority of food allergies in children are caused by few foods, namely cow's milk, egg, wheat, soya, peanut, tree nuts, fish and shellfish ${ }^{1}$. However, as a practising allergist, one needs to have an open mind as allergy can be caused by virtually any food. It is important to report rare allergies to increase awareness and support the diagnosis of new cases should this be suspected. Furthermore, with globalisation and dissemination of cuisines around the world, knowledge about new foods and new allergens is very valuable.

We report the case of a 5-year old boy of Nigerian descent with a history of immediate onset urticaria, periorbital angioedema and vomiting after the ingestion of egusi melon seeds at the age of 6 months. He had a history of urticaria and vomiting on exposure to cow's milk at 3 months of age, and reported similar reactions to coconut, peanut, almond and hazelnut in the first year of life. He had a background of early onset atopic dermatitis, which was recently well managed with mild topical corticosteroids, mild seasonal allergic rhinitis and viral induced wheeze. There was a family history of atopy: father had a history of asthma and allergic rhinitis.

Cow's milk had since been successfully reintroduced into the diet, but he continued to avoid egusi seed, all nuts and coconut, as well as sesame seed due to evidence of sensitisation on blood testing. As egusi seed formed an important part of the family's diet, the family were keen to reintroduce egusi seed if possible, and cashew, coconut or peanut were in second line of priority.

Skin prick tests were performed in clinic and blood was collected for specific IgE testing and the basophil activation test (BAT). The BAT was performed to peanut to confirm the need for food challenge as part of an ongoing research study (Research Ethics Committee reference 10/H0802/44) and to egusi seeds to confirm the diagnosis, following parental consent and child's assent. The BAT was performed as previously described $^{2,3}$ using a peanut extract prepared by ALK-Abello and an in-house prepared egusi seed extract alongside with negative (Roswell Park Memorial Institute (RPMI) 1640 Medium alone) and positive controls, namely anti-IgE and N-formylmethionyl-leucyl-phenylalanine (fMLP) - for details on the methodology see supplementary material. Briefly, dehulled egusi seeds were ground and homogenised in phosphate buffered saline (PBS) for overnight cold extraction. Crude extract was then centrifuged and filtered using Whatman 
paper. Protein precipitation was performed using saturated ammonium sulfate until $80 \%$ saturation was reached. The resulting pellet was dissolved in ultrapure water then dialysed in deionised water overnight at MWCO 3500. BCA assay was performed to determine total protein content of aqueous extract and an SDS-PAGE (Figure E1 ) was used to determine presence and approximate size of proteins in the extract for use in the BAT.

The results of SPT and specific IgE are represented in Table 1. The BAT to peanut was positive, i.e. above the optimal diagnostic cut-off (4.78\% CD63+ Basophils) previously validated in our centre, and the patient was therefore not referred for an oral food challenge, which the family was reassured about as they were anxious about the idea of exposing their child to peanut. The BAT to egusi seeds showed a dose-dependent increase of the expression of CD63 on the surface of basophils with increasing concentration of egusi seed allergen extract with a peak of $73.71 \%$ net $\mathrm{CD}^{+} 3^{+}$basophils at $10,000 \mathrm{ng} / \mathrm{mL}$ (Figure 1 ). A similar doseresponse was also observed for the CD203c stimulation index. Basophil response to both anti-IgE and fMLP controls were detectable, with $61.01 \%$ and $12.71 \%$ net $\mathrm{CD}_{63}{ }^{+}$basophils respectively. The combination of BAT, SPT and the history confirm the diagnosis of egusi seed allergy.

Strict avoidance of peanut, all tree nuts, coconut, sesame seed and egusi seed was advised and a written emergency management plan was given along with emergency medication, consisting of 2 adrenaline autoinjectors and cetirizine.

Egusi (Citrullus mucosospermus), sometimes referred to as egusi melon or egusi watermelon, is part of the Cucurbitacaeae family and is closely related to watermelon ${ }^{4,5}$. It is found in the tropics, from West Africa through to Sudan. Although the flesh of the fruit is dry and bitter, the seeds can be dried and ground and are commonly used to thicken soups in West African cuisine ${ }^{6}$. To our knowledge, this is the first documented case of egusi seed allergy. We were able to confirm the diagnosis suggested by the clinical history with detection of functional IgE to egusi seeds on SPT and the BAT.

In cases of suspected allergy to exotic foods or rare allergens, modified skin prick testing using the implicated food may be the only test available to confirm the allergy. It should also be noted, that in our patient the skin prick test diameters were initially quite small - despite a convincing history of reaction to egusi seeds and then became larger at age 6 years, probably reflecting a more established immune allergic response and demonstrating the importance of a detailed clinical history and the benefit of repeated skin prick testing in children over time. We were fortunate to have access to the BAT, which allowed to defer the OFC to peanut and to further confirm the diagnosis of egusi seed allergy.

Our patient also had a clinical history and/or sensitisation pattern suggestive of allergy to sesame seed, peanut and tree nuts including hazel nut ${ }^{7}$. Cross-reactivity has been described in seed allergy, with common allergenic structures identified between sesame seed, poppy seeds, hazelnuts, rye grain and $\mathrm{kiwi}^{8}$. Crossreactivity has also been described between other members of the Cucurbitacaeae family including pumpkin, pumpkin seed, musk melon, watermelon, cucumber and courgette ${ }^{9}$. Allergens identified in other seed allergies include $2 \mathrm{~S}$ albumin, oleosin, lipid transfer protein and profilin, while profilin, malate dehydrogenase and triose phosphate isomerase and profilin have been identified as major allergens in watermelon allergy ${ }^{8,10}$. However, this requires further research.

In summary, we report for the first time the case of allergy to egusi seeds in an atopic child of Nigerian origin with allergy to other seeds and nuts. This case highlights the need to know and explore less common foods as potential allergens, the importance of modified skin prick testing and the BAT to support the diagnosis of rare food allergies and of awareness about world cuisine and exotic foods as potential allergens.

Erika Harnik, MBBS ${ }^{1}$

Zainab Jama, BSc $\mathrm{BS}^{2,3,4}$

Matthew Kwok, $\mathrm{BSc}^{2,3,4}$

Adam T. Fox, MBBS MD ${ }^{1,2}$ 
Alexandra F. Santos, MD $\mathrm{PhD}^{1,2,3,4}$

${ }^{1}$ Children's Allergy Service, Evelina London Children's Hospital, Guy's and St Thomas' Hospital, London, United Kingdom

${ }^{2}$ Department of Women and Children's Health (Pediatric Allergy), School of Life Course Sciences, Faculty of Life Sciences and Medicine, King's College London, London, United Kingdom

${ }^{3}$ Peter Gorer Department of Immunobiology, School of Immunology and Microbial Sciences, King's College London, London, United Kingdom

${ }^{4}$ Asthma UK Centre in Allergic Mechanisms of Asthma, London, United Kingdom

Table 1 Skin prick test and specific IgE results at age 5 and 6 years.

\begin{tabular}{|c|c|c|c|c|}
\hline Allergen & $\begin{array}{l}\text { Skin prick wheal } \\
\text { diameter }(\mathrm{mm})\end{array}$ & $\begin{array}{l}\text { Skin prick wheal } \\
\text { diameter }(\mathrm{mm})\end{array}$ & $\begin{array}{l}\text { Specific IgE } \\
\left(\mathrm{kU}_{\mathrm{A}} / \mathrm{L}\right)\end{array}$ & $\begin{array}{l}\text { Specific IgE } \\
\left(\mathrm{kU}_{\mathrm{A}} / \mathrm{L}\right)\end{array}$ \\
\hline & 5 years of age & 6 years of age & 5 years of age & 6 years of age \\
\hline Positive control & 4 & 3 & & \\
\hline Negative control & 0 & 0 & & \\
\hline Peanut & 2 & 5 & $\begin{array}{l}\text { Peanut } 6.57 \text { Ara } \mathrm{h} 2 \\
0.22\end{array}$ & $\begin{array}{l}\text { Peanut } 1.35 \text { Ara h } 2 \\
0.05\end{array}$ \\
\hline Almond & 0 & 1 & 2.57 & 1.74 \\
\hline Hazelnut & 4 & 5 & $\begin{array}{l}\text { Hazel nut } 41.3 \text { Cor } \\
\text { a } 917.8 \text { Cor a } 14 \\
75.3\end{array}$ & $\begin{array}{l}\text { Hazelnut } 21.5 \text { Cor a } \\
10.00 \text { Cor a } 911.5 \\
\text { Cor a } 1444.5\end{array}$ \\
\hline Walnut & 0 & 0 & 4.86 & 6.85 \\
\hline Pecan & 5 & 4 & & 0.43 \\
\hline Cashew & 0 & 8 & 22.5 & 7.08 \\
\hline Pistachio & 0 & 6 & & 12.00 \\
\hline Brazil nut & 5 & 7 & 8.88 & 5.35 \\
\hline Pine nut & 0 & 0 & & 0.02 \\
\hline Macadamia & 5 & 10 & & 4.03 \\
\hline Sesame & 3 & 15 & 62.9 & 51.4 \\
\hline $\begin{array}{l}\text { Egusi seed } \\
\text { (modified prick } \\
\text { test) }\end{array}$ & 2 & 6 & & \\
\hline Coconut & & 10 & 15.3 & \\
\hline $\begin{array}{l}\text { House dust mite } \\
\text { DP }\end{array}$ & 3 & & & \\
\hline $\begin{array}{l}\text { House dust mite } \\
\text { DF }\end{array}$ & 3 & & & \\
\hline Birch pollen & 0 & & & \\
\hline Timothy grass & 9 & & & \\
\hline Cat & 0 & & & \\
\hline Dog & 0 & & & \\
\hline
\end{tabular}

Table 1. Skin prick test and specific IgE results aged 5 and 6 years 


\section{Basophil Activation Test to Egusi Seed}

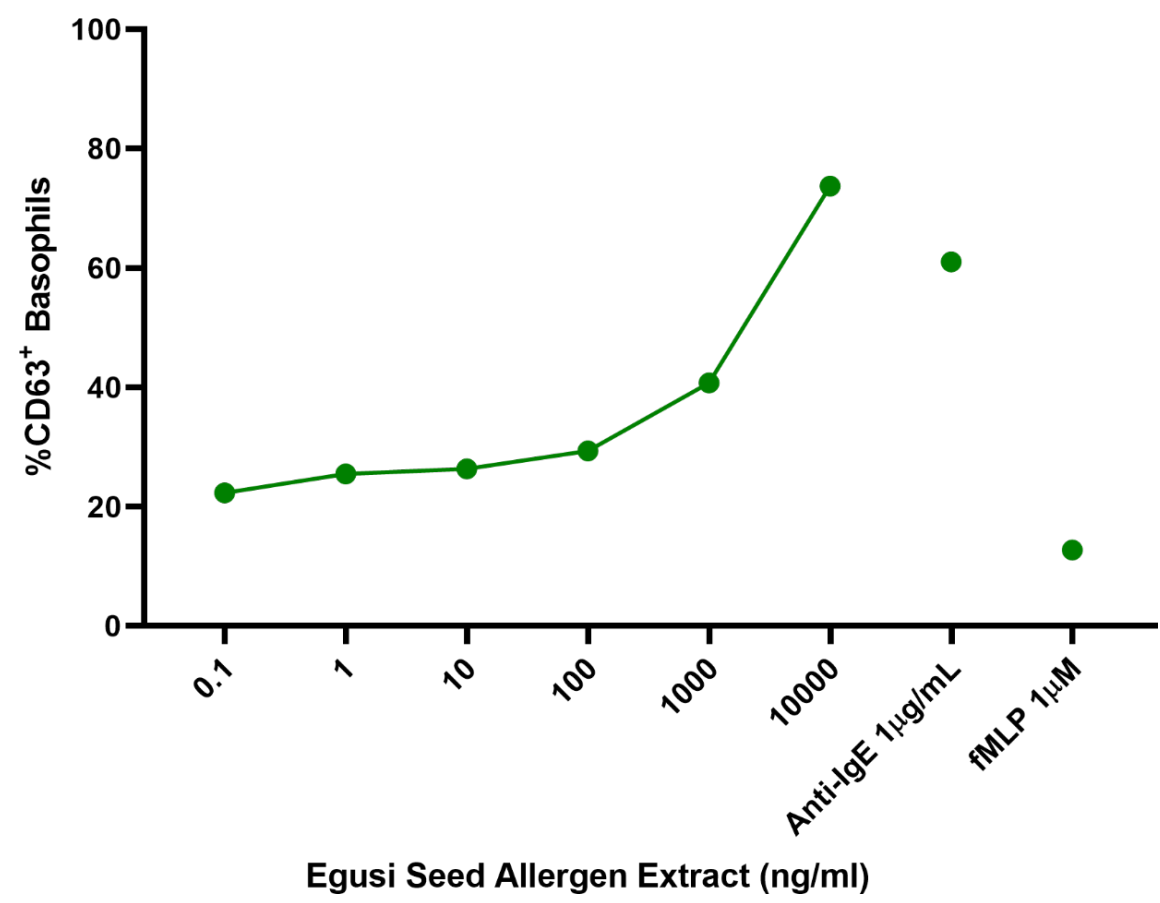

Figure 1. Basophil activation test to egusi seed. A dose response curve illustrating the proportion of $\mathrm{CD} 3^{+}$basophils at increasing concentrations of egusi seed extract from $0.1 \mathrm{ng} / \mathrm{mL}$ to $10,000 \mathrm{ng} / \mathrm{mL}$. Positive controls are represented by anti-IgE (aIgE) and N-Formylmethionyl-leucyl-phenylalanine (fMLP).

\section{References}

1. Gupta RS, Warren CM, Smith BM, et al. The Public Health Impact of Parent-Reported Childhood Food Allergies in the United States.Pediatrics. 2018;142(6).

2. Santos AF, Douiri A, Becares N, et al. Basophil activation test discriminates between allergy and tolerance in peanut-sensitized children. J Allergy Clin Immunol. 2014;134(3):645-652.

3. Santos AF, Du Toit G, O'Rourke C, et al. Biomarkers of severity and threshold of allergic reactions during oral peanut challenges. J Allergy Clin Immunol. 2020.

4. Schoch CL, Ciufo S, Domrachev M, et al. NCBI Taxonomy: a comprehensive update on curation, resources and tools. Database (Oxford). 2020;2020.

5. U.S. National Plant Germplasm System

6. Council NR. Lost Crops of Africa: Vegetables. National Academies Press. 2006;2:158 (155-171).

7. Vocks E, Borga A, Szliska C, et al. Common allergenic structures in hazelnut, rye grain, sesame seeds, kiwi, and poppy seeds.Allergy. 1993;48(3):168-172.

8. Patel A, Bahna SL. Hypersensitivities to sesame and other common edible seeds. Allergy. 2016;71(10):1405-1413.

9. Figueredo E, Cuesta-Herranz J, Minguez A, et al. Allergy to pumpkin and cross-reactivity to other Cucurbitaceae fruits. J Allergy Clin Immunol. 2000;106(2):402-403.

10. Pastor C, Cuesta-Herranz J, Cases B, et al. Identification of major allergens in watermelon. Int Arch Allergy Immunol.2009;149(4):291-298. 